\title{
Prevalence and characterization of plasmids carrying sulfonamide resistance genes among Escherichia coli from pigs, pig carcasses and human
}

Shuyu Wu $\mathrm{W}^{1,2,4}$, Anders Dalsgaard², Anette M Hammerum³ ${ }^{3}$ Lone J Porsbo ${ }^{1}$, Lars B Jensen ${ }^{1 *}$

\begin{abstract}
Background: Sulfonamide resistance is very common in Escherichia coli. The aim of this study was to characterize plasmids carrying sulfonamide resistance genes (sul1, sul2 and sul3) in E. coli isolated from pigs and humans with a specific objective to assess the genetic diversity of plasmids involved in the mobility of sul genes.

Methods: A total of 501 E. coli isolates from pig feces, pig carcasses and human stools were tested for their susceptibility to selected antimicrobial. Multiplex PCR was conducted to detect the presence of three sul genes among the sulfonamide-resistant $E$. coli isolates. Fifty-seven sulfonamide-resistant $E$. coli were selected based on presence of sul resistance genes and subjected to conjugation and/or transformation experiments. S1 nuclease digestion followed by pulsed-field gel electrophoresis was used to visualize and determine the size of plasmids. Plasmids carrying sul genes were characterized by PCR-based replicon typing to allow a comparison of the types of sul genes, the reservoir and plasmid present.

Results: A total of 109/501 isolates exhibited sulfonamide resistance. The relative prevalences of sul genes from the three reservoirs (pigs, pig carcasses and humans) were $65 \%, 45 \%$ and 12\% for sul2, sul1, and sul3, respectively. Transfer of resistance through conjugation was observed in 42/57 isolates. Resistances to streptomycin, ampicillin and trimethoprim were co-transferred in most strains. Class 1 integrons were present in $80 \%$ of sul1-carrying plasmids and $100 \%$ of sul3-carrying plasmids, but only in $5 \%$ of sul2-carrying plasmids. The sul plasmids ranged from 33 to 160-kb in size and belonged to nine different incompatibility (Inc) groups: FII, FIB, I1, FIA, B/O, FIC, N, HI1 and X1. IncFll was the dominant type in sul2-carrying plasmids (52\%), while Incl1 was the most common type in sull and sul3-carrying plasmids (33\% and $45 \%$, respectively). Multireplicons were found associated with all three sul genes.
\end{abstract}

Conclusions: Sul genes were distributed widely in E. coli isolated from pigs and humans with sul2 being most prevalent. Sul-carrying plasmids belonged to diverse replicon types, but most of detected plasmids were conjugative enabling horizontal transfer. IncFll seems to be the dominant replicon type in sul2-carrying plasmids from all three sources.

\section{Background}

High prevalence of sulfonamide resistance has been observed in Gram-negative bacteria from animals and humans all over the world [1-5]. In Denmark,

\footnotetext{
* Correspondence: Iboj@food.dtu.dk

'Department of Microbiology and Risk Assessment, National Food Institute, Technical University of Denmark, Mørkhøj Bygade 19, DK-2860 Søborg, Denmark

Full list of author information is available at the end of the article
}

sulfonamides are one of the most frequently used antimicrobials to treat diseases in pigs and sulfonamide resistance prevalence in Escherichia coli is relatively high along the food chain from pigs to pork and humans $[3,5,6]$. In contrast to the many different resistance genes described for other classes of antimicrobials, so far there are only three genes (sul1, sul2 and sul3) which have been identified encoding sulfonamide 
resistance [4,7]. Sul1 has almost exclusively been found on large conjugative plasmids and on class 1 integrons $[3,6,8,9]$. Sul2 was previously considered to be located on small non-conjugative plasmids, but recently the gene has also been found on a wide range of large conjugative plasmids $[1,8]$ and have been linked to the prevalence of streptomycin resistance [3]. Sul3 was originally described from pigs in Switzerland in 2003 and has since been reported in animals as well as humans in many countries. A recent publication has linked sul3 to non-classic class 1 integrons [10]. However, knowledge about the structure and circulation of plasmids carrying sul3 has yet not been well described yet [7].

Genetic localization of sul genes on efficient mobile genetic structures probably contribute to the wide spread of sulfonamides resistance. Plasmids unavoidably play an important role in carrying and mobilizing sul genes [8]. The identification of plasmids associated with specific sul genes therefore helps understanding the mobilization capability of sul-genes among different bacterial species and enables determination of how sulfonamide resistance disseminates in different environments. Currently little is known about plasmid backbones associated with various sul genes especially in different reservoirs, e.g. animals and human [1,9]. The aims of this study were therefore to investigate the prevalence of the sulfonamide resistance genes (sul1, sul2 and sul3) in $E$. coli through the food chain from pigs to slaughter (pig carcasses) and humans and to assess the genetic diversity of plasmid, based on size and replicon, involved in the mobility of various sul genes from the three sources.

\section{Methods}

\section{Bacterial strain collection}

A total of $501 \mathrm{E}$. coli isolates collected from three sources were included in this study: 150 isolates were obtained in 2007 from fecal samples of Danish pigs as part of the Danish Integrated Antimicrobial Resistance Monitoring and Research Program (DANMAP) [5]; 275 isolates were obtained from pig carcasses in a Danish pig slaughterhouse in November 2007 [11]; and 76 isolates were obtained from stool samples of Danish healthy humans between May and June 2008, of which only two had been travelling abroad within three months before sampling [12].

Sampling and strain isolation for $E$. coli from pig feces has been described previously $[5,11,12]$. Only one isolate was collected from each pig fecal and human stool sample. Multiple isolates were collected from each pig carcass sample, but only representative isolates with distinct pulsed-field gel electrophoresis (PFGE) patterns were included in the characterization of plasmids.

\section{Antimicrobial susceptibility testing}

Antimicrobial resistance profiles for all isolates were determined by an automated microdilution method (Trek Diagnostic Systems, East Grinstead, UK) for 17 antimicrobial agents included in DANMAP [5]. The results were interpreted in accordance with EUCAST guidelines [13], where the Minimum Inhibitory Concentration (MIC) breakpoint for sulfamethoxazole resistance is $>256 \mathrm{mg} / \mathrm{L}$.

\section{Detection of sul genes and integrons}

Multiplex PCR was performed on boiled cell lysates of the sulfonamide-resistant isolates. Primers developed by Kerrn et al. [14] were used for detection of sul1 and sul2 and a new primer-set for sul 3 was designed for this study (sul3-F: 5'-CAGATAAGGCAATTGAGCATGCTCTGC-3', sul3-R: 5'-AGAATGATTTCCGTGACACTGCAATCATT-3'). PCR was performed in a $20 \mu \mathrm{L}$ mixture, including $2 \mu \mathrm{L}$ template DNA, $3 \mu \mathrm{L} 10 \times$ reaction buffer (Ampliqon, Herlev, Denmark); $1 \mu \mathrm{L}$ $\mathrm{MgCl}_{2}$ (25 mM; Ampliqon); $0.25 \mu \mathrm{L}$ dNTPs; $0.25 \mu \mathrm{L}$ Taq Polymerase (50 mM, Ampliqon); $2.5 \mu \mathrm{L}$ forward and reverse primer mixture (volume for sul1:sul2:sul3 = 1:1:2). Amplification was carried out by heating for 5 min at $94^{\circ} \mathrm{C}$, followed by 30 cycles at $94^{\circ} \mathrm{C}$ for $1 \mathrm{~min}$, $68^{\circ} \mathrm{C}$ for $1 \mathrm{~min}$ and $72^{\circ} \mathrm{C}$ for $2 \mathrm{~min}$, followed by $72^{\circ} \mathrm{C}$ for $10 \mathrm{~min}$. The sizes of the amplicon were $433 \mathrm{bp}$ for sul1, 293 bp for sul2 and 569 bp for sul3. Presences of class 1 and class 2 integrons were detected by primers for integrase 1 and integrase 2 described previously $[14,15]$. Positive and negative controls were included in all PCR arrays.

\section{Plasmid-mediated sulfonamide resistance transferability}

A proportion of sulfonamide-resistant $E$. coli isolates (18 from humans, 18 from pig feces and 21 from pig carcasses) representing different sul genes were selected for further plasmid characterization. Conjugation experiments were performed at $37^{\circ} \mathrm{C}$ by filter mating assay using E. coli K12-J53 (nalidixic acid-resistant) as recipient and transconjugants were selected on Mueller-Hinton agar plates supplemented $256 \mathrm{mg} / \mathrm{L}$ sulfamethoxazole and $40 \mathrm{mg} / \mathrm{L}$ nalidixic acid.

When donor strains were resistant to nalidixic acid or resistance plasmid transfer failed in the mating experiments or when plasmid co-transfer occurred, electroporation was done to obtain recipients with single plasmid carrying sul genes. Plasmid DNA was purified by the QIAGEN Plasmid Mini kit (Qiagen, Hilden, Germany) as described by the manufacturer. Purified plasmids were used to transform ElectroMAX $\mathrm{X}^{\mathrm{Tm}} \mathrm{DH} 10 \mathrm{~B}^{\mathrm{m}}$ competent cells (Invitrogen, Paisley, United Kingdom) using a Bio-Rad MicroPulser (Bio-Rad Laboratories, CA, USA) under standard conditions $(1.8 \mathrm{kv}, 180 \Omega$ and 
$25 \mu \mathrm{F})$. Transformants were selected on Mueller-Hinton agar plates supplemented with $256 \mathrm{mg} / \mathrm{L}$ sulfamethoxazole and confirmed to harbor corresponding sul genes by multiplex PCR assay as described earlier.

\section{S1 nuclease digestion of plasmids and PFGE}

S1 nuclease digestion followed by PFGE was performed to visualize and determine the molecular size of plasmids [14]. Agarose plugs were prepared according to the PulseNet protocol [16] except the concentration of the cells was adjusted to $0.83-0.85$ on a Dade Micoscan turbidity meter (Dade Behring, CA, USA). Slices of plugs were digested with $5 \mathrm{U}$ of $\mathrm{S} 1$ nuclease (Promega, Madison, WI, USA) for $45 \mathrm{~min}$ at $37^{\circ} \mathrm{C}$. The plasmids were separated in a $1 \%$ SeaKem Gold agarose (Cambrex, East Rutherford, NJ, USA) gel using the CHEF DR III System (Bio-Rad, Hercules, CA) in $0.5 \times$ Tris-borate EDTA at $14^{\circ} \mathrm{C}$ and an angle of 120 at $6 \mathrm{~V} / \mathrm{cm}$ gradient with pulse ramping from 6.8 to $38.4 \mathrm{~s}$ over $18 \mathrm{~h}$.

\section{Plasmid replicon type determination}

Plasmids from parental and transformant/transconjugant strains were assigned to 18 incompatibility (Inc) groups by PCR-based replicon typing (PBRT) of total DNA using previously described primers and conditions [17]. IncQ was screened as described previously [18]. The presence of IncX1 was investigated using the primers (IncX1-F: 5'-GCAGATTGATTCACGTGAAG-3', IncX1R 5'-CCTCTGAAACCGTATGGTATTC-3'). All positive results generated by multiplex PCR were confirmed using single primer pair.

\section{Results and discussion}

Prevalence of sulfonamide resistant E. coli and sul genes A total of 109 sulfonamide resistant E. coli isolates were detected and prevalences of sulfonamide resistance were $17 \%$ for pig feces $(26 / 150), 18 \%$ from pig carcasses (49/ $275)$ and $45 \%$ from humans stool (34/76) (Table 1). The prevalence of sul1 gene varied from $23 \%$ to $29 \%$ in $E$. coli from the three sources. The sul2 gene was the most prevalent sulfonamide resistance gene found in all of the three sources $(>40 \%)$. The sul3 gene was present alone in $9 \%$ of pig feces and $10 \%$ of pig carcasses, while in human isolates it was detected simultaneously with sul2 in two $E$. coli isolates. The presence of two sul genes was detected in $E$. coli from all sources (18\% from pig feces, $20 \%$ from pig carcasses and $31 \%$ from humans).

A higher prevalence of sul2 than sul1 and sul3 in E. coli from animals and humans has been observed in previous studies in Denmark as well as in other countries $[3,6,14,19,20]$. In the UK, sulfonamide resistance in human E. coli persists undiminished with sul2 maintaining dominant despite that the human usage of sulfonamides had been terminated decades ago[1,2]. We found that sul3 occurred with the lowest prevalence of the three sul genes among all E. coli from the three sources, which corresponds to previous observations $[3,6,9,21,22]$. The higher prevalence of combined sul genes in human $E$. coli isolates compared with food animal isolates was also observed in earlier studies $[3,6]$. This is likely due to the acquisition of additional genes from different sources (animals, food and environment), as well as the selective pressure by the human's consumption of antimicrobial agents.

Sulfonamides are widely used in Danish veterinary practice. Combined formulations of sulfonamide/trimethoprim have been frequently used in Danish pig production [5]. This may explain why sulfonamide resistance occurs with high prevalence in E. coli isolates from Danish pigs. From the previous epidemiological study of the human isolates included in this investigation no strong correlation between prevalence of sulfonamide resistance in isolates of human origin and human usage of sulfonamides could be found.

\section{Transferability of sul genes}

A total of 57 sulfonamide-resistant E. coli isolates (18 from pig feces, 21 from pig carcasses and 18 from humans) were included for conjugation assay and plasmid analysis. Conjugative plasmids were successfully transferred from 42 isolates (82\%), including 22 isolates where the sul plasmids were co-transferred with another plasmid (data not shown). Electro-transformation was conducted to ensure transconjugants containing only

Table 1 Prevalence of sul1, sul2 and sul3 genes in sulfonamide-resistant $E$. coli isolated from pig feces, pig carcasses and human stools

\begin{tabular}{|c|c|c|c|c|c|}
\hline \multirow[t]{2}{*}{ Origin } & \multirow[t]{2}{*}{ No. of isolates tested } & \multicolumn{4}{|c|}{ No. of isolates with sul genes (percentage) } \\
\hline & & sul1 only & sul2 only & sul3 only & two sul genes \\
\hline Human stool & 26 & $6(23 \%)$ & $12(46 \%)$ & 0 & $8(31 \%)^{a}$ \\
\hline Pig carcass & 49 & $13(27 \%)$ & $21(43 \%)$ & $5(10 \%)$ & $10(20 \%)^{b}$ \\
\hline Pig feces & 34 & $10(29 \%)$ & $15(44 \%)$ & $3(9 \%)$ & $6(18 \%)^{c}$ \\
\hline
\end{tabular}

\footnotetext{
${ }^{a}$ Six strains were positive for both sul1 and sul2; two strains contained both sul2 and sul3.

b Seven strains contained both sul1 and sul2; one strain contained sul1 and sul3; and two strains harbored sul2 and sul3.

' Six strains contained both sul1 and sul2.
} 
one plasmids encoding for sul-resistance. This was performed for the 22 isolates containing multiple conjugative plasmids, including $9 \mathrm{E}$. coli isolates with nonconjugative plasmids and 6 isolates showing resistance to nalidixic acid. The results showed, that 53/57 transconjugants/transformants obtained a single sul gene, while the remaining four isolates (all from humans) contained single plasmids of different sizes carrying both sul1 and sul2 genes (Table 2).

Additional phenotypically expressed resistances were co-transferred with sulfonamide resistance by 55 plasmids $(96 \%)$, resulting in diverse resistance patterns (Table 2) indicating possible co-selection for all three tested sulfonamide resistance genes. Overall, the most frequently co-transferred resistances were to streptomycin (54\%), ampicillin (51\%) and trimethoprim (46\%). These three resistances were co-transferred more frequently by sul 2 plasmids than those by sul1 and sul3 plasmids with highest frequency for streptomycin and ampicillin resistance (both 79\%), indicating that the use of these antimicrobials possibly contribute to the predominance of the sul2 gene via co-selection, which corroborates previous studies by Bean et al. [1,2]. Tetracycline resistance was co-transferred in 16 plasmids carrying sul1 and/or sul2 genes. Chloramphenicol resistance was found to be co-transferred in 7 plasmids with 6 of them being sul3 associated. The strong link between chloramphenicol resistance and sul3 presence has already been reported for Salmonella and E. coli $[9,23]$.

The presence of intI1 was detected in sul1 (71\%), sul2 (17\%) and sul3 (100\%) -carrying plasmids from all three sample reservoirs (Table 2). Two out of 28 intI1-carrying plasmids could not be transferred by conjugation. Only one of 57 isolates carrying the sul2 plasmid contained intI2. It is interesting to note, that all sul3 plasmids were conjugative and harbored intI1 as recently detected [9]. The association of sul3-carrying conjugative plasmids with integrons in E. coli isolates from pigs (carcass or feces) could probably facilitate the further spread of this gene to other bacteria and reservoirs via food chain.

\section{Plasmid analysis and replicon typing}

S1 nuclease digestion followed by PFGE showed that the 15 plasmids carrying single sul1 genes ranged from 33$160 \mathrm{~kb}$ in size. Replicon typing demonstrated seven different incompatibility groups (I1, N, FIB, FIA, HI1, FII and $\mathrm{B} / \mathrm{O}$ ) for the plasmids (Table 2). IncI1 was the most common group, accounting for 5 intI1-containing conjugative plasmids (from pig feces and carcasses). Out of the six sul1 plasmids originating from human specimens, four belonged to FI or FII type (three plasmids had multireplicons FIA-FIB or FII-FIB), one plasmid belonged to $\mathrm{B} / \mathrm{O}$ and one plasmid could not be assigned. This replicon profile in human E. coli isolates seems different from those found in E. coli from pigs which mostly belonged to I1 and N. Due to the limited number of strains obtained from each source, a firm conclusion on whether specific replicon profiles are associated with pigs or humans would require the testing of additional strains.

The 25 sul2-carrying plasmids ranged from $33-120 \mathrm{~kb}$ in size. Five different incompatibility groups (FII, B/O, FIB, I1 and FIA) were demonstrated (Table 2). Among them FII was the predominant replicon type (52\%) and distributed equally in $E$. coli from the three sources. This is in contrast to a study in the UK where the FII replicon was not detected in 33 sul2-carrying plasmids in E. coli isolated from hospitals [1]. The 15 FII plasmids were similar in size (33-55 kb) and none contained intI1. However, the plasmids were associated with various resistance phenotypes and conjugation capabilities. It is possible that they represent the same plasmid backbone circulating in pigs and humans. The $\mathrm{B} / \mathrm{O}$ replicon type was found in plasmids from $E$. coli isolated from both human and pig, but with different resistance profiles, indicating they are different plasmids sharing the same backbone. FIA, FIB, and I1 replicons were also found to be associated with sul2 genes. Three sul2-carrying plasmids were negative for all the tested Inc groups. For the four plasmids carrying both sul1 and sul2 genes, two harbored the FIB replicon alone, one harbored FIB-FII and one had FIA-FIB-FII multireplicons.

Overall, IncF (FIA, FIB, FIC and FII) seemed to be the most common replicon associated with sul2, accounting for $72 \%$ sul2-carrying plasmids (21/29). IncF plasmids, which are considered having a narrow host range and being conjugative, seemed to be well adapted to E. coli as it was found in more than $50 \%$ of E. coli strains from different sources (especially FIB and FII) $[24,25]$. Localization on common plasmids such as IncF could indicate transmission between the three reservoirs studied.

The 11 sul3-carrying plasmids ranged from 33-115 kb in size. Replicon typing detected five different incompatibility groups: I1, FII, FIB, FIC and X1 (Table 2). IncI1 was found to be the most prevalent (45\%) and all were conjugative and associated with class 1 integrons. The IncI1 plasmids had similar sizes, but differed in the resistance profiles. FII, X1 and FIB-FIC were also found to be associated with the sul3 gene. Two sul3-carrying plasmids were negative for all the tested Inc groups.

When comparing plasmid size and the resistance phenotype, we found that E. coli isolates with larger sized plasmids did not always show resistance to a higher number of different antimicrobials. For instance, the 120 kb-sized plasmid contained in isolate 70-141-6 was only 
Table 2 Characterization of sul genes and plasmids in $57 \mathrm{E}$. coli isolates.

\begin{tabular}{|c|c|c|c|c|c|c|c|}
\hline $\begin{array}{l}\text { sul gene located } \\
\text { on plasmids }\end{array}$ & Strain ID & Sample source & Inc group & $\begin{array}{l}\text { Plasmid size } \\
\text { (kb) }\end{array}$ & Co-transferred resistance & Conjugative & Integrase \\
\hline$\overline{\text { sul1 }}$ & $70-7-3$ & pig feces & 11 & 60 & TET TMP & Yes & $\ln t / 1$ \\
\hline sul1 & 70-10-1 & pig feces & 11 & 78 & STR SPE TET & Yes & $\ln t / 1$ \\
\hline sul1 & 70-13-2 & pig feces & 11 & 140 & STR SPE & Yes & $\ln t / 1$ \\
\hline sul1 & 70-58-1 & pig feces & 11 & 78 & SPE TET & Yes & $\ln t / 1$ \\
\hline sul1 & V3-s1-8-4 & pig carcass & 11 & 78 & TET TMP & Yes & $\ln t / 1$ \\
\hline sul1 & V2-f2-2 & pig carcass & N & 33 & TET TMP & Yes & $\ln t / 1$ \\
\hline sul1 & $v 2-s 3-3-10$ & pig carcass & $N$ & 33 & TET TMP & Yes & $\ln t / 1$ \\
\hline sul1 & $v 2-s 3-2-3$ & pig carcass & $\mathrm{FIB}$ & 105 & SPE STR & Yes & $\ln t / 1$ \\
\hline sul1 & 3847 & human stool & $\mathrm{FIB}$ & 80 & AMP SPE STR & Yes & $\ln t / 1$ \\
\hline sul1 & v4-s1-20-3 & pig carcass & $\mathrm{HI} 1$ & 160 & SPE STR TET & Yes & $\ln t / 1$ \\
\hline sul1 & $70-7-2$ & pig feces & FII & 45 & AMP & Yes & \\
\hline sul1 & 3796 & human stool & $\mathrm{FIA}, \mathrm{FIB}$ & 95 & AMP AUG GEN TMP & No & \\
\hline sul1 & 3880 & human stool & FIA, FIB & 78 & TMP & No & \\
\hline sul1 & 3849 & human stool & $\mathrm{FIB}, \mathrm{FII}$ & 80 & STR & No & \\
\hline sul1 & 3846 & human stool & $\mathrm{B} / \mathrm{O}$ & 55 & AMP AUG & Yes & \\
\hline sult & 70-138-3 & pig feces & Unknown & 85 & STR TMP & No & $\ln t / 1$ \\
\hline sul1 & 3806 & human stool & Unknown & 40 & AMP TET TMP & Yes & $\ln t / 1$ \\
\hline sul2 & 70-13-7 & pig feces & $\mathrm{FII}$ & 55 & AMP & Yes & \\
\hline sul2 & $70-165-18$ & pig feces & FII & 45 & AMP & Yes & \\
\hline sul2 & 70-13-9 & pig feces & FII & 55 & AMP STR & Yes & \\
\hline sul2 & $70-56-3$ & pig feces & FII & 55 & AMP STR TMP & Yes & \\
\hline sul2 & $70-58-2$ & pig feces & FII & 40 & AMP STR TMP & Yes & \\
\hline sul2 & $v 2-f 3-2$ & pig carcass & FII & 50 & AMP & Yes & \\
\hline sul2 & v2-s1-3-5 & pig carcass & FII & 45 & AMP STR & Yes & \\
\hline sul2 & v3-s1-2-8 & pig carcass & FII & 55 & AMP STR & Yes & \\
\hline sul2 & v4-s3-17-3 & pig carcass & FII & 40 & AMP STR & Yes & \\
\hline sul2 & v2-f3-6 & pig carcass & FII & 55 & AMP STR TET TMP & Yes & \\
\hline sul2 & v2-s1-1-10 & pig carcass & FII & 55 & AMP GEN STR TMP & Yes & \\
\hline sul2 & 3783 & human stool & FII & 50 & AMP TMP & $--^{\mathrm{a}}$ & \\
\hline sul2 & 3816 & human stool & FII & 33 & AMP STR TET TMP & No & \\
\hline sul2 & 3837 & human stool & FII & 33 & AMP STR TET TMP & No & \\
\hline sul2 & 3859 & human stool & FIl & 55 & STR & - & \\
\hline sul2 & $70-141-6$ & pig feces & $\mathrm{FIB}$ & 120 & TET & Yes & \\
\hline sul2 & $70-166-11$ & pig feces & $\mathrm{B} / \mathrm{O}$ & 80 & TMP & Yes & $\ln t / 2$ \\
\hline sul2 & $70-10-6$ & pig feces & $\mathrm{B} / \mathrm{O}$ & 70 & AMP STR TET & Yes & $\ln t / 1$ \\
\hline sul2 & $70-11-5$ & pig feces & $\mathrm{B} / \mathrm{O}$ & 78 & AMP STR SPE TMP & Yes & \\
\hline sul2 & 3841 & human stool & $\mathrm{B} / \mathrm{O}$ & 55 & AMP STR & Yes & \\
\hline sul2 & V2-s1-1-8 & pig carcass & 11 & 50 & AMP SPE STR TMP & - & \\
\hline sul2 & 3834 & human stool & $F|A, F| B$ & 60 & AMP GEN STR TET TMP & - & $\ln t / 1$ \\
\hline sul2 & V2-s3-1-8 & pig carcass & Unknown & 45 & AMP STR & Yes & \\
\hline sul2 & 3815 & human stool & Unknown & 80 & AMP SPE STR & Yes & $\ln t / 1$ \\
\hline sul2 & 3810 & human stool & Unknown & 95 & STR & - & $\ln t / 1$ \\
\hline sult+2 & 3853 & human stool & $\mathrm{FIB}$ & 130 & AMP CHL STR TET TMP & No & $\ln t / 1$ \\
\hline sult+2 & 3823 & human stool & $\mathrm{FIB}$ & 139 & AMP STR TMP & - & \\
\hline sult+2 & 3872 & human stool & $\mathrm{FIB}, \mathrm{FII}$ & 100 & STR TET TMP & No & \\
\hline sul1+2 & 3881 & human stool & $\mathrm{FIA}, \mathrm{FIB}, \mathrm{FII}$ & 110 & GEN STR TET TMP & No & \\
\hline$\overline{s u l 3}$ & 70-13-1 & pig feces & 11 & 80 & $\mathrm{CHL}$ & Yes & $\ln t / 1$ \\
\hline sul3 & 70-11-1 & pig feces & 11 & 78 & - - & Yes & $\ln t / 1$ \\
\hline sul3 & $v 2-s 3-3-6$ & pig carcass & 11 & 78 & - & Yes & $\ln t / 1$ \\
\hline sul3 & $v 2-s 3-2-4$ & pig carcass & 11 & 78 & CHL SPE STR TMP & Yes & $\ln t / 1$ \\
\hline
\end{tabular}


Table 2: Characterization of sul genes and plasmids in $57 \mathrm{E}$. coli isolates. (Continued)

\begin{tabular}{|c|c|c|c|c|c|c|c|}
\hline sul3 & v4-s3-3-4 & pig carcass & 11 & 55 & $\mathrm{CHL}$ & Yes & $\ln t / 1$ \\
\hline sul3 & V3-s3-2-4 & pig carcass & $X 1$ & 115 & AMP NEO SPE TMP & Yes & $\ln t / 1$ \\
\hline sul3 & v4-f1-2 & pig carcass & FII & 78 & $\mathrm{CHL}$ & Yes & $\ln t / 1$ \\
\hline sul3 & v4-s1-20-4 & pig carcass & $\mathrm{FIB}, \mathrm{FIC}$ & 65 & SPE & Yes & $\ln t / 1$ \\
\hline sul3 & 70-8-1 & pig feces & $\mathrm{FIB}, \mathrm{FIC}$ & 78 & SPE & Yes & Int/1 \\
\hline sul3 & v4-s1-20-6 & pig carcass & Unknown & 55 & $\mathrm{CHL}$ & Yes & $\ln t / 1$ \\
\hline sul3 & $v 2-s 1-1-9$ & pig carcass & Unknown & 33 & $\mathrm{CHL}$ & Yes & $\ln t / 1$ \\
\hline
\end{tabular}

AMP: ampicillin; AUG: amoxillin + clavulanat; CHL: chloramphenicol GEN: gentamicin; SPE: spectinomycin; STR: streptomycin; NEO: neomyxin; SMX: sulfamethoxazole; TET: tetracycline; TMP: trimethoprim.

a conjugation not conducted.

associated with resistance to tetracycline (Table 2). However, isolates with smaller plasmids of only $33-\mathrm{kb}$ size (isolates 3816 and 3837) showed resistance to ampicillin, streptomycin, tetracycline and trimethoprim. This indicates that resistance genes only account for a small part of the plasmid gene sequence and more studies are needed to determine the contents and function of such plasmids.

The findings of diverse incompatibility groups among various sul genes indicate that sul genes have been able to transfer into multiple plasmid backbones on multiple occasions, or that the plasmid backbones have diversified extensively since the acquisition of sul genes [1]. The IncF in our study was the most prevalent, carrying FII alone or in combination with FIA or/and FIB or/and FIC (multireplicon). This suggests that these plasmids are evolving through replicon sequence divergence, mosaicism and replicon co-integration in resolution process [26]. As human stays on the top of the food chain, the sul plasmids from healthy human reflects a more mixed population compared with pig or pork (partly represented by pig carcasses) also reflecting other reservoirs that connected to the farm to fork chain.

Sul-carrying plasmids in pig feces and on pig carcasses represent a pool of resistance genes that may transfer to human via the food chain, the most important non-human reservoir for transmission of antimicrobial resistance to humans. In fact, the colonization of sulfonamide-resistant $E$. coli from animal sources (chicken or pig) into the human gut has been successfully demonstrated in both in vitro and in vivo studies $[27,28]$. The transfer of the sul2 gene from an E. coli strain of a pig origin to a sulfonamide-sensitive $E$. coli strain of human origin was demonstrated in the intestine of mice and transfer of sul2 has also been detected among E. coli in the human intestine [15]. By combining all these date it could be speculated that consumption of pork contaminated with sulfonamide-resistant $E$. coli could result in the transfer of sul genes from pigs to humans.

\section{Conclusions}

To our knowledge, this is the first study to assess the plasmid replicons involved in various sul genes from different reservoirs. The diverse replicon profiles indicate no clear association between the replicon types and specific sul genes or sample sources. However, the localization of sul genes on wide spread replicons such as IncF is very likely to contribute to the dissemination of sulfonamide resistance. In addition, all sul3-carrying plasmids were found to be conjugative and associated with class 1 integrons. This underscores the potential of sul3 to become more widespread in the future.

\section{Acknowledgements}

Henrik Hasman from the National Food Institute, Technical University of Denmark is thanked for his help to design the primer for Inc $X 1$ and helpful discussions during the study. Alessandra Carattoli from Istituto Superiore di Sanita, Rome, Italy is appreciated for the encouragement and discussion during the study. Hanne-Dorthe Emborg and Vibeke F. Jensen from the National Food Institute, Technical University of Denmark are acknowledged for providing information from the DANMAP and VetStat databases. Karin S Pedersen and Frank Hansen are thanked for excellent technical assistance at SSI. We also thank Hans O. Jørgensen and Inger M. Giversen at the Danish Armed Forces Health Services and Erling Døssing from the Infirmeriet in Holstebro for establishing the contact to the recruits. We are grateful to the recruits without whom the study would not have been possible. This study was supported by a grant from the EU Marie Curie Program TRAINAU (MEST-CT-2004-007819).

\section{Author details}

'Department of Microbiology and Risk Assessment, National Food Institute, Technical University of Denmark, Mørkhøj Bygade 19, DK-2860 Søborg, Denmark. ${ }^{2}$ Department of Veterinary Disease Biology, Faculty of Life Sciences, University of Copenhagen, Stigbøjlen 4, DK-1870 Frederksberg C, Denmark. ${ }^{3}$ National Center for Antimicrobials and Infection Control, Statens Serum Institut, 5 Artillerivej, DK-2300 Copenhagen S, Denmark. ${ }^{4}$ Shuyu Wu's present address changed to: US-CDC China Office, Suite 403, Dongwai Diplomatic Building, 23 Dongzhimenwai Dajie, Beijing 100600, China.

\section{Authors' contributions}

WS performed the experiment and was responsible for the data analysis and writing the manuscript. AD and LE were involved in the study design and preparation of the manuscript. AMH and LJP participated in the study design and data analysis. All authors read and approved the final manuscript.

\section{Competing interests}

The authors declare that they have no competing interests. 
Received: 29 March 2010 Accepted: 30 July 2010

Published: 30 July 2010

\section{References}

1. Bean DC, Livermore DM, Hall LM: Plasmids imparting sulfonamide resistance in Escherichia coli: implications for persistence. Antimicrob Agents Chemother 2009, 53:1088-1093.

2. Bean DC, Livermore DM, Papa I, Hall LM: Resistance among Escherichia coli to sulphonamides and other antimicrobials now little used in man. $J$ Antimicrob Chemother 2005, 56:962-964.

3. Hammerum AM, Sandvang D, Andersen SR, Seyfarth AM, Porsbo LJ, Frimodt-Moller N, Heuer OE: Detection of sul1, sul2 and sul3 in sulphonamide resistant Escherichia coli isolates obtained from healthy humans, pork and pigs in Denmark. Int J Food Microbiol 2006, 106:235-237.

4. Skold O: Resistance to trimethoprim and sulfonamides. Vet Res 2001, 32:261-273.

5. DANMAP: DANMAP 2007-Use of antimicrobial agents and occurrence of antimicrobial resistance in bacteria from food animals, foods, and humans in Denmark Danish Institute for Food and Veterinary Research edn. Danish Institute for Food and Veterinary Research,Cpenhagen, Denmark 2008.

6. Trobos M, Jakobsen L, Olsen KE, Frimodt-Moller N, Hammerum AM, Pedersen $K$, Agerso Y, Porsbo L, Olsen JE: Prevalence of sulphonamide resistance and class 1 integron genes in Escherichia coli isolates obtained from broilers, broiler meat, healthy humans and urinary infections in Denmark. Int J Antimicrob Agents 2008, 32:367-369.

7. Perreten V, Boerlin P: A new sulfonamide resistance gene (sul3) in Escherichia coli is widespread in the pig population of Switzerland. Antimicrob Agents Chemother 2003, 47:1169-1172.

8. Radstrom P, Swedberg G, Skold O: Genetic analyses of sulfonamide resistance and its dissemination in gram-negative bacteria illustrate new aspects of R plasmid evolution. Antimicrob Agents Chemother 1991, 35:1840-1848.

9. Antunes P, Machado J, Sousa JC, Peixe L: Dissemination of sulfonamide resistance genes (sul1, sul2, and sul3) in Portuguese Salmonella enterica strains and relation with integrons. Antimicrob Agents Chemother 2005 49:836-839.

10. Antunes $P$, Machado J, Peixe L: Dissemination of sul3-containing elements linked to class 1 integrons with an unusual $3^{\prime}$ conserved sequence region among Salmonella isolates. Antimicrob Agents Chemother 2007, 51:1545-1548.

11. Wu S, Dalsgaard A, Vieira AR, Emborg H-D, Jensen LB: Prevalence of tetracycline resistance and genotypic analysis of populations of Escherichia coli from animals, carcasses and cuts processed at a pig slaughterhouse. International Journal of Food Microbiology 2009, 135.254-259.

12. DANMAP: DANMAP 2008-Use of antimicrobial agents and occurrence of antimicrobial resistance in bacteria from food animals, foods, and humans in Denmark 2009.

13. The European Committee on Antimicrobial Susceptibility TestingEUCAST. [http://www.eucast.org/]

14. Kerrn MB, Klemmensen T, Frimodt-Moller N, Espersen F: Susceptibility of Danish Escherichia coli strains isolated from urinary tract infections and bacteraemia, and distribution of sul genes conferring sulphonamide resistance. J Antimicrob Chemother 2002, 50:513-516.

15. Sandvang D, Aarestrup FM, Jensen LB: Characterisation of integrons and antibiotic resistance genes in Danish multiresistant Salmonella enterica Typhimurium DT104. FEMS Microbiol Lett 1997, 157:177-181.

16. CDC: One-day (24-48 h) standardized laboratory protocol for molecular subtyping of Escherichia coli O157:H7, non-typhoidal Salmonella serotypes, and Shigella sonnei by pulsed field gel electrophoresis (PFGE). PulseNet PFGE Manual Centers for Disease Control and Prevention, Atlanta, Ga 2004.

17. Carattoli A, Bertini A, Villa L, Falbo V, Hopkins KL, Threlfall EJ: Identification of plasmids by PCR-based replicon typing. J Microbiol Methods 2005, 63:219-228.

18. Gotz A, Pukall R, Smit E, Tietze E, Prager R, Tschape H, van Elsas J D, Smalla K: Detection and characterization of broad-host-range plasmids in environmental bacteria by PCR. Appl Environ Microbiol 1996, 62:2621-2628.

19. Blahna MT, Zalewski CA, Reuer J, Kahlmeter G, Foxman B, Marrs CF: The role of horizontal gene transfer in the spread of trimethoprim- sulfamethoxazole resistance among uropathogenic Escherichia coli in Europe and Canada. J Antimicrob Chemother 2006, 57:666-672.

20. Frank T, Gautier V, Talarmin A, Bercion R, Arlet G: Characterization of sulphonamide resistance genes and class 1 integron gene cassettes in Enterobacteriaceae, Central African Republic (CAR). J Antimicrob Chemother 2007, 59:742-745.

21. Guerra $B$, Junker $E$, Helmuth R: Incidence of the recently described sulfonamide resistance gene sul3 among German Salmonella enterica strains isolated from livestock and food. Antimicrob Agents Chemother 2004, 48:2712-2715.

22. Saenz Y, Brinas L, Dominguez E, Ruiz J, Zarazaga M, Vila J, Torres C: Mechanisms of resistance in multiple-antibiotic-resistant Escherichia coli strains of human, animal, and food origins. Antimicrob Agents Chemother 2004, 48:3996-4001.

23. Bischoff KM, White DG, Hume ME, Poole TL, Nisbet DJ: The chloramphenicol resistance gene $\mathrm{cm} / \mathrm{A}$ is disseminated on transferable plasmids that confer multiple-drug resistance in swine Escherichia coli. FEMS Microbiol Lett 2005, 243:285-291.

24. Boyd EF, Hill CW, Rich SM, Hartl DL: Mosaic structure of plasmids from natural populations of Escherichia coli. Genetics 1996, 143:1091-1100.

25. Johnson TJ, Wannemuehler YM, Johnson SJ, Logue CM, White DG, Doetkott $C$, et al: Plasmid replicon typing of commensal and pathogenic Escherichia coli isolates. Appl Environ Microbiol 2007, 73:1976-1983.

26. Carattoli A: Resistance plasmid families in Enterobacteriaceae. Antimicrob Agents Chemother 2009, 53(6):2227-2238.

27. Trobos M, Lester $\mathrm{CH}$, Olsen JE, Frimodt-Moller N, Hammerum AM: Natural transfer of sulphonamide and ampicillin resistance between Escherichia coli residing in the human intestine. J Antimicrob Chemother 2009, 63:80-86.

28. Linton AH, Howe K, Bennett PM, Richmond MH, Whiteside EJ: The colonization of the human gut by antibiotic resistant Escherichia coli from chickens. J Appl Bacteriol 1977, 43:465-469.

doi:10.1186/1751-0147-52-47

Cite this article as: Wu et al:: Prevalence and characterization of plasmids carrying sulfonamide resistance genes among Escherichia coli from pigs, pig carcasses and human. Acta Veterinaria Scandinavica 2010 $52: 47$.

\section{Submit your next manuscript to BioMed Central and take full advantage of:}

- Convenient online submission

- Thorough peer review

- No space constraints or color figure charges

- Immediate publication on acceptance

- Inclusion in PubMed, CAS, Scopus and Google Scholar

- Research which is freely available for redistribution 